\title{
Review
}

\section{Atherosclerotic Vascular Disease and Risk Factors in Turkey: From Past to Present}

\author{
Lale Tokgözoğlu and Ergün Barış Kaya
}

Department of Cardiology, Hacettepe University Faculty of Medicine, Ankara, Turkey

\begin{abstract}
The prevalance of atherosclerotic vascular disease is unexpectedly high in Turkey despite its young population, with a median age of 29. The mean total cholesterol is lower than in Western European countries; however, smoking is very prevalant, the incidence of metabolic syndrome is high and obesity, diabetes and hypertension are becoming a major problem, especially in women. Having these risk factors as well as lower HDL levels leads to high cardiovascular morbidity and mortality at younger ages. This problem is expected to become worse with increasing industrialisation, adaptation to Western diets, a sedentary lifestyle and increasing obesity. A National Heart Health Policy has been developed to overcome this epidemic and combat the risk factors and reduce the burden of atherosclerotic vascular disease.
\end{abstract}

J Atheroscler Thromb, 2008; 15:286-291.

Key words; Atherosclerosis, Prevention, Risk factors, Coronary artery disease

Atherosclerotic vascular disease is the leading cause of morbidity and mortality throughout Europe and most parts of the world ${ }^{1)}$. There has been some success in decreasing the incidence of atherosclerotic vascular disease in Western Europe by agressive risk factor modification, whereas the incidence is still on the rise in Eastern Europe. However, in most countries, the success in decreasing conventional risk factors, such as smoking and hyperlipidemia, is offset by the increasing incidence of obesity and diabetes.

The risk factors leading to atherosclerotic vascular disease have been well defined. The Framingham Study was the first study to show that classical risk factors such as smoking, hyperlipidemia, hypertension and diabetes are the main determinants of atherosclerotic vascular disease ${ }^{2)}$. The INTERHEART Study further expanded our views about the importance of lifestyle factors such as exercise, daily intake of fruit and vegetables and psychosocial risk factors in addition to classically proven risk factors in causing myocardial infarction, a major complication of atheroscle-

Address for correspondence: Lale Tokgözoğlu, FESC, FACC Hacettepe University Faculty of Medicine Cardiology Department, 06100, Ankara, Turkey

E-mail: lalet@hacettepe.edu.tr

Received: July 29, 2008

Accepted for publication: August 8, 2008 $\operatorname{rosis}^{3)}$.

Turkey is a large country with a population of 70.5 million and a median age of 29 according to 2007 statistics $^{4)}$. Despite having a young population, the prevalance of atherosclerotic vascular disease is unexpectedly high. The coronary mortality rates are about 5 per 100 person years, which is higher than most European countries ${ }^{5)}$. With the ageing of the population, these rates are expected to rise about $4.7 \%$ per year even if other risk factors remain stable. Unfortunately, the other risk factors are not remaining stable, therefore the predicted increase in coronary artery disease incidence is $7 \%$ per year for the next ten years.

Prior to 1990 , the prevalance of risk factors in Turkey was not well known. The Turkish Adult Risk Factor Survey (TEKHARF study) was one of the the first large studies designed to look at the distribution of risk factors. In this study, 3687 subjects representative of the adult population over 20 years of age were chosen from seven geographic regions stratified for age, gender and urban-rural distribution ${ }^{6}$. The Turkish Heart Study (THS) was also a pioneer study, exploring plasma lipids, lipoproteins, and selected apolipoproteins in approximately 9,000 men and women from six different regions of Turkey with markedly different diets ${ }^{7}$. The Turkish Diabetes Epidemiology Study (TURDEP) was a large population-based survey, 
determining the prevalence of diabetes and impaired glucose tolerance throughout Turkey, including both urban and rural populations in the northern, southern, western, eastern, and central regions of the country ${ }^{8}$. This study included 24,788 subjects over 20 years of age. Other studies such as the Prevalence, awareness, treatment and control of hypertension in Turkey (PatenT) study ${ }^{9)}$, the treatment and control of hypertension in the Turkish population (TURKSAHA) study ${ }^{10)}$ and the prevalence of metabolic syndrome among Turkish adults (METSAR) study followed, and reported more data on risk factors in the Turkish population. The information obtained from these studies enabled understanding of the reasons for the high prevalance of cardiovascular disease in the country. The risk factor profile and its contribution to atherosclerotic vascular disease will be discussed below according to data from these studies.

\section{Lipid Profile}

According to the TEKHARF study, the mean concentration of total cholesterol was $185 \mathrm{mg} / \mathrm{dL}$ in men and $192 \mathrm{mg} / \mathrm{dL}$ in women, showing that the cholesterol levels of the population were not too high compared to Western Europe and United States. It is well known that total cholesterol levels increase with age in all populations. In the 20-29 -year-old group, Turkish adults total cholesterol levels were $150 \mathrm{mg} /$ $\mathrm{dL}$ but showed a steep rise of $25 \%$ in the next two decades. This shows that Turkish people start adulthood with lower cholesterol levels but with increasing age, sedentary lifestyle and unhealthy eating, their cholesterol levels have increased significantly by the time they reach middle age.

The prevalance of cholesterol levels over $200 \mathrm{mg} /$ $\mathrm{dL}$ was found to be $25 \%$ in TEKHARF. Similiar values were seen in The Turkish Heart Study where 32\% of men and $22 \%$ of women had cholesterol levels over $200 \mathrm{mg} / \mathrm{dL}$. These studies confirmed that hypercholesterolemia was not as prevalant in Turkey as in Western populations.

Hypertriglyceridemia, defined as levels above 150 $\mathrm{mg} / \mathrm{dL}$, was found in $39 \%$ of men and $29 \%$ of women in the initial TEKHARF study. Unfortunately, over a period of 10 years, a significant increase in triglyceride levels in the population was observed, especially in women, parallel to increased abdominal obesity.

The Turkish Heart Study was the first to observe that HDL levels were significantly low in Turks ${ }^{7}$. They reported that mean HDL cholesterol was 38.3 $\mathrm{mg} / \mathrm{dL}$ in men and $45.5 \mathrm{mg} / \mathrm{dL}$ in women. They also reported that children have better HDL levels until adolescence, when both boys and girls experience a $10-20 \%$ decrease ${ }^{7)}$. HDL levels were also found to be low in Turks living abroad starting a debate on whether HDL levels are genetically low in the Turkish population, however, several factors influence HDL levels. In multivariate analysis of the TEKHARF study, age, smoking, waist circumference, physical inactivity, insulin levels and CRP were all found to be associated with low $\mathrm{HDL}^{6}$. It seems that the high prevalance of smoking, high triglyceride and apoB levels, and the increasing epidemic of abdominal obesity are all contributing to low HDL levels. Since the publication of these reports, HDL levels have become higher in Turkey due to lifestyle factors and socioeconomic changes. In addition, new simpler methodologies report about 10\% higher HDL levels.

Whether there is a genetic susceptibility to low HDL levels in Turkey has been questioned by Mahley's group who observed high hepatic lipase levels in Turks, elevated by $25-30 \%$, which may contribute to low HDL levels ${ }^{11)}$. We recently looked at the genetic basis of low HDL in patients with angiographically documented coronary artery disease, and HDL levels less than $40 \mathrm{mg} / \mathrm{dL}$ compared to healthy controls with normal HDL ${ }^{12)}$. However, when we looked at polymorphisms of the hepatic lipase gene, we found no difference in prevalance between coronary artery patients with low HDL and healthy controls with normal HDL levels. In the same study, we tried to evaluate the genetic determinants of low HDL in patients with angiographically documented coronary artery disease and low HDL compared to healthy controls with normal HDL. HDL levels were higher in B2 allele carriers of CETP Taq1b polymorphism. The frequency of the ApoE2 allele was higher in patients without coronary artery disease and low LDL levels were observed in E2 allele carriers. Both LDL and total cholesterol levels were higher in TT genotype of UCP2 (rs660339) polymorphism. ABCA1 rs2230808 GG genotype frequency was higher in the control group, than in patients with coronary artery disease and low HDL, however, this is just information is from a pilot study and clearly, larger studies are needed to explain the genetic basis of coronary artery disease in Turkey.

\section{Hypertension and Salt Intake}

Altun et al. ${ }^{9)}$ carried out a population-based crosssectional epidemiological survey in 2003, determining the distribution of blood pressure and the prevalence, awareness, treatment and control of hypertension in Turkey (PatenT Study), from 26 cities in seven geo- 
graphical provinces of Turkey, with proportional representation of urban and rural populations. Hypertension (HT) was defined as mean systolic $\mathrm{BP} \geq 140$ $\mathrm{mmHg}$ or mean diastolic $\mathrm{BP} \geq 90 \mathrm{mmHg}$, or previously diagnosed and/or taking antihypertensive drugs. Among the 4910 participants, the overall age- and sex-adjusted prevalence of hypertension in Turkey was $31.8 \%$, and it was higher in women than in men (36.1\% versus $27.5 \%, p<0.001)$. The Turkish adult population is relatively young and population statistics show that approximately one-third of the adult population is between 18 and 30 years old, whereas only $15 \%$ is above the age of 60 . The PatenT study, consistent with the universal data, showed that the prevalence of HT increased with age, reaching $70-80 \%$ after age 60, however, split analysis documented that only $35 \%$ of hypertensives were above 60 years of age. The remaining $53 \%$ of hypertensives were in the middle age group and a non-negligible proportion of $12 \%$ was in the 18-29 years age group. These results point out that the middle age group bears the burden of HT. In the whole group, $32.2 \%$ of the patients had never had their BP measured. While $40.7 \%$ of patients with hypertension were aware of their diagnosis, only $31.1 \%$ of the patients were receiving pharmacologic treatment and only $8.1 \%$ of all hypertensives and $20 \%$ of pharmacologically treated patients had their BP under control. The TURKSAHA study ${ }^{10)}$ also reported that the rate of successful blood pressure control was low among hypertensive patients receiving treatment in the Turkish population. These data show that hypertension is a highly prevalent but inadequately treated health problem in Turkey.

According to the TEKHARF study, systolic blood pressure was found to be the single most powerful predictive risk factor of coronary morbidity and mortality in both genders at 5 years and in a multivariate analysis at 10 years follow-up ${ }^{5,13)}$. When the cut-off point of systolic blood pressure was taken as $130 \mathrm{mmHg}$, the age-adjusted relative risk in men and women was approximately 3.6 and 3.9, respectively. Coronary risk is increased by $14 \%$ for every increment of $10 \mathrm{mmHg}$ in systolic blood pressure. During the baseline survey of the study, hypertension, defined as systolic pressure $>140 \mathrm{mmHg}$ or diastolic pressure $>85 \mathrm{mmHg}$ or being treated with antihypertensive medication, was found in one-third of adults. The prevalence of hypertension was $36 \%$ in men and $49 \%$ in women aged over 30 years. This prevalence was $43 \%$ in men and $56 \%$ in women in the $40-69$ age groups ${ }^{14)}$. Mean systolic and diastolic blood pressures standardised for age 35-64 years were $125 / 80 \mathrm{mmHg}$ in men and 133/82 $\mathrm{mmHg}$ in women in 1990. After 10-year follow-up of this cohort, mean blood pressure measurements exhibited a net rise of $7 / 4 \mathrm{mmHg}$ in women and $5 / 3$ $\mathrm{mmHg}$ among men. Onat et al. ${ }^{15)}$ showed that both systolic and diastolic pressures were significantly associated with indices of obesity and central obesity in adult men and women over a wide age range. Body mass index (BMI) was a strong independent marker of systolic and diastolic pressures in women, while in men the determinant value of the waist/hip ratio was equivalent to BMI. Each increment of $1 \mathrm{~kg} / \mathrm{m}^{2}$ of BMI was associated in men with an increase of over 8 and $16 \mathrm{mmHg}$ in diastolic and systolic pressure, respectively, regardless of the age group.

\section{Smoking}

Smoking cigarettes is one of the most important health problems in Turkey. While the prevalence of smoking began to decline in both genders in Western countries from the 70 s to 90 s, cigarette consumption increased by about $20 \%$ in Turkey ${ }^{16}$. The first report from the TEKHARF study documented that $60 \%$ of men and $19 \%$ of women were smokers ${ }^{17)}$. The 10 -year follow-up from this cohort showed that smoking prevalence was reduced by $18 \%$ in men and increased by $24 \%$ in females ${ }^{6}$. In the TEKHARF study, smoking was shown to be the most significant independent marker of elevated plasma fibrinogen levels in both genders. Not only current smoking, but also past smoking was significantly associated with increased coronary morbidity and mortality. In a populationbased survey (TURDEP), the prevalence of smoking was $51 \%$ in men and $11 \%$ in women ${ }^{8}$. All studies, the Turkish Heart Study (THS), TEKHARF, and TURDEP reported that smoking was an important health issue for the country. Turkey has long been a nation of smokers and passive smokers, with no regulations to prohibit smoking in public places, but today this has changed with a law banning smoking in public venues, such as all educational, health, commercial, social, cultural, sports and entertainment facilities, including the corridors of these buildings. A law enacted by the Turkish Government in May 19, 2008 banned smoking in all enclosed areas of the previously mentioned venues.

\section{Diabetes}

The prevalence of diabetes mellitus (DM) is increasing worldwide. The World Health Organization (WHO) estimates that there will be about 300 million people with DM by the year $2025^{18)}$. The prevalence of DM in Turkey has also been rising at 
an unpredictable rate, along with obesity. In the TURDEP study, which included 24788 subjects (age $\geq 20$ years), the overall crude prevalence of diabetes was $7.2 \%$ (previously undiagnosed, 2.3\%) and impaired glucose tolerance (IGT) was $6.7 \%{ }^{8)}$. Extrapolating these results to the population census, nearly $2.6 \mathrm{mil}-$ lion adults in Turkey may have diabetes, of whom 0.8 million may be unaware of their disease. The prevalence of DM in males was lower than females, $6.2 \%$ vs $8.0 \%(p<0.0001)$, respectively. Both DM and IGT rates were higher in urban than rural subjects. Multiple logistic regression analysis showed that increasing age, BMI, waist-hip ratio, hypertension, and familial diabetes in both sexes, education in men, and living in the south in women were positively associated with DM. A recent analysis of TEKHARF study participants (3401 participants, aged 48.2 \pm 12 years) reported that the prevalence of DM in Turkish adults was estimated as 2.89 million $(11.0 \%$ of the population aged $\geq 35$ years). Over a mean follow-up of 5.9 years, incident al DM developed in 223 subjects, yielding an incidence per 1000 person-years of 11.0 in women and 12.4 in men. This corresponded to a 300,000 annual incidence. Abdominal obesity and age in both genders, hypertension, and low HDL-cholesterol in men alone were significantly associated with the development of DM. Diabetes mellitus was found to be a significant and independent predictor of fatal and nonfatal CHD, with an RR of 1.81 (95\% CI 1.19; 2.75), after adjustment for sex, age, hypertension, waist circumference, serum total cholesterol and smoking status. This study also showed that insulin resistance appeared to be a weak determinant of DM in Turkish women while abdominal obesity was the main determinant.

\section{Metabolic Syndrome and Obesity}

There is a universal increase in the prevalance of obesity and abdominal obesity which is also having an impact in Turkey. According to the TEKHARF study, $14 \%$ of men and $30 \%$ of women over the age of 20 have a body mass index above $30 \mathrm{~kg} / \mathrm{m}^{219)}$. Obesity is a major problem in Turkish postmenaposal women. Body mass index is a strong independent marker of systolic and diastolic blood pressure in women and a moderate predictor of dyslipidemia in both genders ${ }^{15}$. When NCEP criteria are used, one out of 30 adults have metabolic syndrome in Turkey according to the TEKHARF Study. It has been shown that the NCEP definition of metabolic syndrome (MS) underestimates the risk of developing diabetes and coronary risk in the Turkish population. For this reason, lower cut-offs for waist circumerence in men $(95 \mathrm{~cm})$ and imparied fasting glucose $(100 \mathrm{mg} / \mathrm{dL})$ have been suggested in the Turkish population. In the METSAR study, the prevalence of MS (using NCEP Adult Treatment Panel-III criteria) was determined both in urban and rural populations in seven geographical regions of Turkey ${ }^{20)}$. The study included 2108 men and 2151 women with a mean age of $40.9 \pm 14.9$ years (range 20-90). The prevalence of MS was 33.9\% and differed significantly in men (28\%) and women (39.6\%). The prevalence of this syndrome increased with age in men, from $10.7 \%$ in people aged $20-29$ years to $49 \%$ in those aged over 70 years. The prevalence increased with age in women, from $9.6 \%$ in subjects aged $20-$ 29 years to $74.6 \%$ in those aged $60-69$ years, and decreased to $68.6 \%$ in those over 70 years of age. The prevalence of MS was similar in urban $(33.8 \%)$ and rural $(33.9 \%)$ population. This high prevalence rate in the Turkish population highlights the importance of this syndrome in terms of public health.

\section{What did We Learn fom the Recent EUROASPIRE III Study?}

The recently completed EUROASPIRE III Study that was carried out in 22 European countries, including Turkey, evaluated patients hospitalized with the diagnosis of coronary artery disease and documented their lifestyle and risk factors ${ }^{21)}$. Overall throughout Europe, a significant increase in lifestyle-related risk factors such as obesity and diabetes was observed despite major increases in medication use. This study was extremely important in documenting the risk factor profile for each country. According to EUROASPIRE III, the mean age of patients hospitalized with coronary artery disease in Turkey was less than 50 in 20\% of cases, the youngest in Europe. Although only 35\% of patients had high LDL levels, $50 \%$ had low HDL levels in this study. The prevalance of obesity was 35\% in this group of patients and $25 \%$ did no physical activity at all outside work. Diabetes prevalance was $33 \%$ and blood pressure was on target in only 35\%. These striking numbers reveal how poorly we are doing with risk-factor modification, especially lifestyle factors, even in patients with documented coronary artery disease.

\section{Discussion}

Although Turkey is a country with a young population, the prevalance of atherosclerotic vascular disease and its mortality is unexpectedly high. This can be explained by the risk factor profile summarized 
above. Overall; the high smoking prevalance, obesity, especially in women, leading to hypertension and diabetes, and lower HDL levels related to these factors override the fact that hypercholesterolemia is not as prevalant as in Western Europe. According to the TEKHARF Study, the leading independent predictors of coronary events and death are systolic blood pressure, total/HDL cholesterol ratio, diabetes and central obesity ${ }^{6}$. Increased physical inactivity and trends toward consuming Western-type fast food is making these risk factors worse. For this reason, in 2006, a National Heart Health Policy Document was prepared with the participation of the Ministry of Health and Turkish Society of Cardiology. In this document, the current situation was assessed and successful models, such as the North Karelia project in Finland, were discussed. It was emphasised that between 1990 and 2005 , there was a $5-6 \%$ increse in coronary artery disease incidence, which is predicted to increase to $7 \%$ per year in the next 10 years, therefore, a goal was set to decrease the rate of increase to $2 \%$ per year. To achieve this, priorities were set for the public health policy. The three priorities were determined to be smoking, hypertension and obesity. Major public health campaigns have been started for this purpose, one of which, aimed to increase hypertension awareness and education, was named ' 12 to 8 '. This campaign resulted in a $7 \%$ increase in the awareness of hypertension in the general public. In addition, in 2008, a law was passed banning smoking in restaurants and public places. These steps are in accord with the 2005 Luxemburg Declaration of the European Union in which National Heart Health policies are recommended for European countries. Turkey was one of the first European countries to have a National Heart Health Policy. Recently, the impact of prevention on reducing the burden of cardiovascular disease using the NHANES IV database has been published, showing that $63 \%$ of myocardial infarctions and $31 \%$ of strokes could be prevented if all eligible patients underwent risk factor modification ${ }^{22)}$. These data show the need for preventional cardiology programs conducted by multidisciplinary teams. Although we still have a long way to go, we hope that by implementing these policies, the burden of cardiovascular disease in our country can be decreased.

\section{References}

1) Viles-Gonzalez JF, Fuster V, Badimon JJ: Atherothrombosis: a widespread disease with unpredictable and lifethreatening consequences. Eur Heart J, 2004; 25:11971207
2) Anderson KM, Wilson PW, Odell PM, Kannel WB: An updated coronary risk profile. A statement for health professionals. Circulation, 1991; 83:356-362

3) Yusuf S, Hawken S, Ounpuu S, Dans T, Avezum A, Lanas F, McQueen M, Budaj A, Pais P, Varigos J, Lisheng L; INTERHEART Study Investigators: Effect of potentially modifiable risk factors associated with myocardial infarction in 52 countries (the INTERHEART study): casecontrol study. Lancet, 2004; 364:937-952

4) www.tuik.gov.tr.

5) Onat A: Risk factors and cardiovascular disease in Turkey. Atherosclerosis, 2001; 156:1-10

6) Onat A, Keles I, and Cetinkaya A: Prevalence of all-cause and coronary mortality in Turkish adults as assessed by 10-year follow-up data of the Turkish adult risk factor study. Arch Turk Soc Cardiol, 2001; 29:8-19 [in Turkish, summary in English]

7) Mahley RW, Palaoğlu KE, Atak Z, Dawson-Pepin J, Langlois AM, Cheung V, Onat H, Fulks P, Mahley LL, Vakar F, Ozbayrakcı S, Gökdemir O, Winklers W: Turkish Heart Study: lipids, lipoproteins, and apolipoproteins. J Lipid Res, 1995; 36:839-859

8) Satman I, Yilmaz T, Sengül A, Salman S, Salman F, Uygur S, Bastar I, Tütüncü Y, Sargin M, Dinççag N, Karsidag K, Kalaça S, Ozcan C, King H: Population-based study of diabetes and risk characteristics in Turkey: results of the turkish diabetes epidemiology study (TURDEP). Diabetes Care, 2002; 25:1551-1556

9) Altun B, Arici M, Nergizoğlu G, Derici U, Karatan O, Turgan C, Sindel S, Erbay B, Hasanoğlu E, Cağlar S; for the Turkish Society of Hypertension and Renal Diseases: Prevalence, awareness, treatment and control of hypertension in Turkey (the PatenT study) in 2003. J Hypertens, 2005; 23:1817-1823

10) Abaci A, Oguz A, Kozan O, Toprak N, Senocak H, Deger N, Sahin M, Sur H, Fici F, Erol C: Treatment and control of hypertension in Turkish population: a survey on high blood pressure in primary care (the TURKSAHA study). J Hum Hypertens, 2006; 20:355-361

11) Bersot TP, Vega GL, Grundy SM, Palaoglu KE, Atagündüz P, Ozbayrakci S, Gökdemir O, Mahley RW: Elevated hepatic lipase activity and low levels of high density lipoprotein in a normotriglyceridemic, nonobese Turkish population. J Lipid Res, 1999; 40:432-438

12) Tokgözoğlu L, Alikaşifoğlu M, Salancı BV, Kaya B, Tülümen E, Deniz A, Aytemir K, Kabakcı G, Oto A, Sönmez K, and Özkutlu H: Genetics of low HDL in Turkish coronary artery disease patients. 77 th Congress of the European Atherosclerosis Society oral presentation. Atherosclerosis, 2008; suppll 9:7

13) Onat A, Dursunoğlu D, Sansoy V: Relatively high coronary death and event rates in Turkish women. Relation to three major risk factors in five-year follow-up of cohort. Int J Cardiol, 1997; 61:69-77

14) Onat A, Sansoy V, and Yildirim B: Blood pressure levels in Turkish adults: 8-year trends, rate of treatment, relationship to other risk factors and to coronary disease. Arch Turk Soc Cardiol, 1999; 27:136-142

15) Onat A, Sansoy V: Systolic and diastolic blood pressure related to six other risk parameters in Turkish adults: 
strong correlation with relative weight. Int J Cardiol, 1998; 63:295-303

16) Hodoğlugil U, Mahley RW: Smoking and obesity make a bad problem worse: genetics and lifestyle affect high density lipoprotein levels in Turks. Anadolu Kardiyol Derg, 2006; 6:60-67

17) Onat A, Şenocak M, Örnek E, Gözükara Y, Şurdum-Avci G, Karaaslan Y: Türkiye'de erişkinlerde kalp hastalığı ve risk faktörleri sıklığı taraması: 5. Hipertansiyon ve sigara içimi. Türk Kardiyol Dern Ars, 1991; 19:169-177

18) King H, Aubert RE, Herman WH: Global burden of diabetes, 1995-2025: prevalence, numerical estimates, and projections. Diabetes Care, 1998; 21:1414-1431

19) Onat A: Obesity in Turkish adults: prevalence, validity as coronary risk factor and interrelation with other risk factors. Int J Angiol, 1995; 4:94-98

20) Kozan O, Oguz A, Abaci A, Erol C, Ongen Z, Temizhan A, Celik S: Prevalence of the metabolic syndrome among Turkish adults. Eur J Clin Nutr, 2007 61:548-553

21) Presented in ESC 2007 Vienna. www.escardio.org.

22) Kahn R, Robertson RM, Smith R, Eddy D: The impact of prevention on reducing the burden of cardiovascular disease. Circulation: 2008 